\title{
The Role of Infliximab Biosimilar CT-P13 in Inflammatory Bowel Disease
}

\author{
Devika Kapuria $^{1 *}$ and Rajiv Chhabra ${ }^{2}$ \\ ${ }^{1}$ Department of Internal Medicine, University of Missouri, Kansas City, USA; ${ }^{2}$ Department of Gastroenterology, University of Missouri, \\ Kansas City, USA
}

\begin{abstract}
The advent of targeted biologic therapies for debilitating disorders such as Crohn's disease (CD) and Ulcerative Colitis (UC) has changed management and significantly improved outcomes. However, biologic agents are expensive, and the introduction of biosimilar medications for the treatment of inflammatory bowel diseases presents a lower-cost alternative. In this review, the mechanism of action, pharmacokinetics, efficacy and adverse effects associated with biosimilar CT-P13 in the treatment of inflammatory bowel disease are discussed.
\end{abstract}

\section{Introduction}

The advent of targeted biologic therapies for debilitating disorders such as Crohn's disease (CD) and ulcerative colitis (UC) has significantly changed management and improved outcomes in patients suffering from these diseases. ${ }^{1,2}$ In particular, the use of tumor necrosis factor-alpha (TNF- $\alpha$ ) antagonists, such as infliximab, adalimumab, golimumab and certolizumab, has been shown to induce clinical remission and prevent structural damage, thereby decreasing the need for steroid therapy, hospitalizations and surgeries for patients with inflammatory bowel diseases (IBD). ${ }^{3}$ Unfortunately, biologic agents, though effective, are expensive. The mean cost to a commercial insurer of one infliximab infusion is approximately $\$ 2,800 .{ }^{4}$ Biosimilars, however, bring us a step closer towards achieving cost-effectiveness in the management of IBDs, with a predicted reduction in cost by up to $70 \%$ for anti-TNF therapy. 5,6

The United States' Food and Drug Administration (FDA) has defined a biosimilar as a biologic product that is highly similar to the reference product, notwithstanding minor differences in clinically-inactive components and for which there are no clinically meaningful differences between the biologic product and the

Keywords: Inflammatory bowel disease; Biosimilar; Biologic agents; CTP13.

Abbreviations: CD, Crohn's disease; UC, Ulcerative colitis; TNF- $\alpha$, tumor necrosis factor-alpha; IBD, inflammatory bowel disease; FDA, Food and Drug Administration; PLANETAS, Programme evaLuating the Autoimmune disease iNvEstigational drug cT-p13 in AS patients; PLANETRA, Programme evaLuating the Autoimmune disease iNvEstigational drug cT-p13 in RA patients; EMA, European Medical Agencies; ADCC, antibody-dependent cell cytotoxicity; PK, pharmacokinetics; ADA, antidrug antibody; $\mathrm{C}_{\max }$, maximum concentration; $\mathrm{AUC}$, area under curve; CDAI, Crohn's disease activity index; CRP, c-reactive protein.

Received: July 11, 2016; Revised: November 16, 2016; Accepted: November 28, 2016 *Correspondence to: Devika Kapuria, University of Missouri, Kansas City, 2301 Holmes Street, Kansas City 64108, USA. Tel: (301) 402-1952, Fax: (301) 451-9160 E-mail: devika.kapuria@gmail.com

How to cite this article: Kapuria D, Chhabra R. The Role of Infliximab Biosimilar CT-P13 in Inflammatory Bowel Disease. J Explor Res Pharmacol 2017;2(1):1-6. doi: 10.14218/JERP.2016.00016 innovator product in terms of safety, purity and efficacy. ${ }^{7}$ Biosimilars are distinguishable from generic drugs as the manufacturing process is significantly more complex, requiring several steps, including the growth of a vector, the presence of a host cell expression system, cell expansion, a protein recovery mechanism, purification and, finally, drug formulation. ${ }^{8}$ CT-P13 is a biosimilar of reference infliximab, which is a chimeric monoclonal antibody against TNF- $\alpha$. The formulation of CT-P13 is identical to that of infliximab, with similar pharmacological characteristics.

The majority of data demonstrating biosimilarity between infliximab and CT-P13 has been derived from two pivotal rheumatologic trials. First, the PLANETAS (Programme evaLuating the Autoimmune disease iNvEstigational drug cT-p13 in AS patients) was a phase I randomized controlled trial (RCT) comparing CT-P13 with infliximab in patients with ankylosing spondylitis. Second, the PLANETRA (Programme evaLuating the Autoimmune disease iNvEstigational drug cT-p13 in RA patients) was a phase III RCT comparing CT-P13 with infliximab RMP in patients with rheumatoid arthritis. These were each randomized, double-blinded, multicenter, parallel group trials with results compared as far out as 54 weeks. With the absence of head-to-head trials for infliximab versus CT-P13 for IBD, evidence from these trials regarding pharmacokinetic equivalence, adverse effects and immunogenicity is currently being extrapolated to IBD studies, given the similar clinically relevant mechanisms of action.

Although many biosimilars for infliximab are undergoing phase II and III trials, and many more are in the pipeline for adalimumab, this review article mainly discusses the infliximab biosimilar CT-P13 in the treatment of IBD. The CT-P13 biosimilar to infliximab (Celltrion Inc.) was first approved by the European Medical Agencies (EMA) for patients with IBD in $2013 .{ }^{9}$ Other countries that have since approved the use of biosimilars to infliximab include Brazil, Colombia, Japan, South Korea, Venezuela (Remsima ${ }^{\circledR}$ Celltrion) and India (BOW015-Ranbaxy). Finally, the United States' FDA approved the use of Remsima for all indications for infliximab in April 2016.

The aim of this review is to describe the mechanism of action, pharmacokinetics, efficacy, immunogenicity and safety of CT-P13 in IBD. 
Table 1. Studies included in the review

\begin{tabular}{|c|c|c|c|c|c|c|c|c|c|}
\hline \multirow{3}{*}{$\begin{array}{l}\text { Study } \\
\text { (Reference No.) }\end{array}$} & \multicolumn{2}{|c|}{ IBD } & \multirow{3}{*}{ Brand } & \multirow{3}{*}{$\begin{array}{l}\text { Follow-up, } \\
\text { weeks }\end{array}$} & \multicolumn{4}{|c|}{ Efficacy } & \multirow{3}{*}{$\begin{array}{l}\text { Safety, adverse } \\
\text { events }\end{array}$} \\
\hline & \multirow{2}{*}{ UC, $n$} & \multirow{2}{*}{$\mathrm{CD}, n$} & & & \multicolumn{2}{|c|}{ Clinical response } & \multicolumn{2}{|c|}{ Remission } & \\
\hline & & & & & $C D$ & UC & $C D$ & UC & \\
\hline Gecse et $a l^{8}$ & 84 & 126 & $\begin{array}{l}\text { Inflectra }^{\circledR} \\
\text { (Hospira, UK) }\end{array}$ & 30 & $\begin{array}{l}77 \% \\
\text { week } 14\end{array}$ & $\begin{array}{l}77 \% \\
\text { week } 14\end{array}$ & $\begin{array}{l}49.1 \% \\
\text { week } 14\end{array}$ & $\begin{array}{l}67.6 \% \\
\text { week } 14\end{array}$ & $17.1 \%$ week 30 \\
\hline Farkas et al ${ }^{10}$ & 21 & 18 & CT-P13 & 8 & $37.5 \%$ & $20 \%$ & $50 \%$ & $66.6 \%$ & $7 \%$ \\
\hline Kang et $a l^{11}$ & 9 & 8 & CT-P13 (Celltrion) & 8 & $66.7 \%$ & $100 \%$ & $66.7 \%$ & $100 \%$ & $5 \%$ \\
\hline Park et $a l^{12}$ & 78 & 95 & Remsima (Celltrion) & 30 & $79.5 \%$ & $72.2 \%$ & $59 \%$ & $37 \%$ & $10.9 \%$ \\
\hline Keil et $a l^{13}$ & 22 & 30 & $\begin{array}{l}\text { CT-P13 (Remsima, } \\
\text { Inflectra) }\end{array}$ & 14 & $100 \%$ & $54 \%$ & $100 \%$ & $40 \%$ & $7 \%$ \\
\hline Jahnsen et $a l^{14}$ & 32 & 46 & Remsima (Celltrion) & 14 & - & $79 \%$ & - & $56 \%$ & $19 \%$ \\
\hline Jung et $a l^{15}$ & 51 & 59 & CT-P13, not mentioned & 54 & $87.5 \%$ & $75 \%$ & $100 \%$ & $50 \%$ & $0 \%$ \\
\hline
\end{tabular}

\section{Methods}

A bibliographic search was performed in PubMed using the following terms: biosimilars, CT-P13, infliximab, ulcerative colitis, Crohn's disease, and inflammatory bowel disease. The search was limited to English language only. References from manual search of selected papers were also included, along with abstracts from Digestive Disease Week 2016 and the European Crohn's and Colitis Organization 2016. Ultimately, a total of 7 studies were included in this review (Table 1). ${ }^{\mathbf{8}, 10-15}$

\section{Mechanism of action}

The mechanism of action of infliximab and other TNF- $\alpha$ inhibitor drugs is based on the inhibition of activity of the pro-inflammatory cytokine TNF- $\alpha$. TNF exists in two forms: transmembrane TNF (tmTNF), which is expressed on the cell surface; and soluble TNF (sTNF), which has been cleaved and released. Binding of TNF- $\alpha$ to its receptors triggers a cascade of pro-inflammatory signaling pathways, resulting in cellular apoptosis (as shown in intestinal epithelial cells) and activation and secretion of pro-inflammatory cytokines. ${ }^{16}$ (Fig. 1)

A mechanism common to all anti-TNF- $\alpha$ monoclonal antibodies is the binding and neutralization of TNF; however, there are certain other mechanisms that are stipulated to be instrumental in IBD, as outlined below.

\section{Reverse signaling}

Reverse signaling is the triggering of pathways that reduce apoptosis and inhibit pro-inflammatory cytokine expression when antiTNF- $\alpha$ antibody binds to a cell expressing tmTNF. Infliximab and CT-P13 were shown to exhibit highly comparable rates of reverse signaling. ${ }^{17}$

\section{Antibody-dependent cell cytotoxicity (ADCC)}

ADCC is mediated by the Fc region of the TNF- $\alpha$ antibody (coating a target cell), which then binds to an $\mathrm{Fc}$ receptor on a natural killer cell in order to induce lysis of the target cell. ${ }^{18,19}$ Currently, ADCC is generally considered unlikely to be a major contributor to the action of infliximab in IBD. ${ }^{20,21}$

\section{Induction of regulatory macrophages}

Induction of certain macrophages can lead to reduced T cell proliferation in an Fc-dependent manner, which has been exhibited by both infliximab and adalimumab. ${ }^{22,23}$ It is uncertain, however, whether CT-P13 exhibits this mechanism of action, but it does exhibit a degree of wound healing similar to that of infliximab.

\section{Pharmacokinetics (PKs)}

PK evaluation of CT-P13 in IBD has been reported in only one study to date. ${ }^{20}$ In that study, the mean trough levels for CT-P13 were 24.8, 18.4 and $4.8 \mu \mathrm{g} / \mathrm{mL}$ in $\mathrm{CD}$ and $19.3,36.2$ and $3.3 \mu \mathrm{g} /$ $\mathrm{mL}$ in $\mathrm{UC}$ at 2, 6 and 15 weeks respectively. Patients with previous infliximab exposure were reported to have lower early therapeutic levels (TLs) as compared to infliximab-naïve patients. Antidrug antibody (ADA) positivity in infliximab-naïve $v s$-exposed patients was $24.2 \%$ vs $38.5 \%$ at 14 weeks.

The PLANETAS study reported steady state PKs (area under curve $[\mathrm{AUC}]$ and maximum concentration $\left[\mathrm{C}_{\max }\right]$ ) as equivalent for CT-P13 and infliximab $(32675.8 \mu \mathrm{gh} / \mathrm{mL}$ and $147 \mu \mathrm{g} / \mathrm{mL} v s$ $31359.3 \mu \mathrm{gh} / \mathrm{mL}$ and $144.8 \mu \mathrm{g} / \mathrm{mL}$ ). ADA negativity was found to be associated with higher geometric means of $A U C$ and $\mathrm{C}_{\max }$ than in the mean population; however, the ratios of geometric means remained near $100 \% .{ }^{21}$ The study also showed similar $\mathrm{C}_{\max }$ for both CT-P13 and infliximab, with the $\mathrm{C}_{\max }$ being $111.88 \mu \mathrm{g} / \mathrm{mL}, 97.91$ $\mu \mathrm{g} / \mathrm{mL}$ and $90.25 \mu \mathrm{g} / \mathrm{mL}$, and $105.07 \mu \mathrm{g} / \mathrm{mL}, 96.20 \mu \mathrm{g} / \mathrm{mL}$ and $85.25 \mu \mathrm{g} / \mathrm{mL}$ at weeks 2,6 and 14 respectively. The ADA negative subset had geometric mean values of $96.7 \mu \mathrm{g} / \mathrm{mL}$ and $91.6 \mu \mathrm{g} / \mathrm{mL}$ respectively for CT-P13 and infliximab at week $22 .{ }^{24}$

Serum levels of CT-P13 have been investigated using commercially available ELISA kits for infliximab, with encouraging results. Malickova et al demonstrated good correlation of CT-P13 serum trough levels between three commonly available assays for infliximab. $^{25}$

\section{Efficacy}

The efficacy of CT-P13, similar to that of infliximab, can be defined by its capability to induce clinical remission and response, mucosal healing and biochemical response. Gecse et al enrolled 


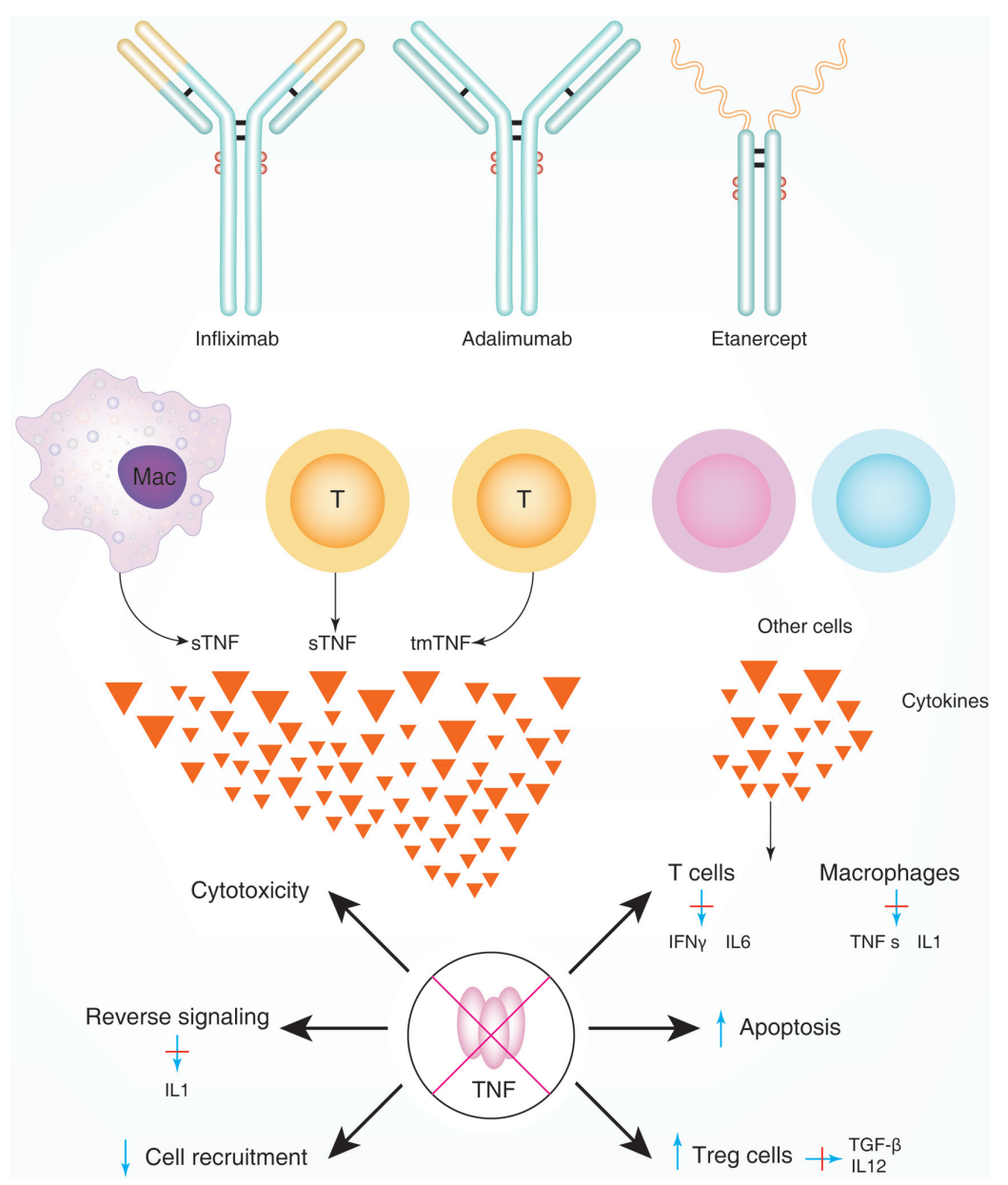

Fig. 1. Mechanism of action of TNF- $\alpha$ inhibitors. sTNF: soluble TNF, tmTNF: transmembrane TNF, T: T cells, IL 1: Interleukin 1, IL 6: Interleukin 6, TGF- $\beta$ : Transforming growth factor $\beta$, IL 12: Interleukin 12, IFN Y: Interferon Y.

210 patients, including 126 with $\mathrm{CD}$ and 84 with $\mathrm{UC}$, in a multicenter, prospective cohort study lasting 30 weeks. ${ }^{20}$ The study found achievement of clinical remission (defined as Crohn disease activity index [CDAI] of $<150$ points or no fistula drainage in $\mathrm{CD}$ and partial Mayo score of $<3$ points) and of clinical response (defined as decrease in CDAI of $>70$ points or at least $50 \%$ reduction in number of draining fistulas and decrease in partial Mayo score of $>3$ points). The simple endoscopic score for CD and Mayo score for UC was used to assess mucosal healing. Up to $77 \%(84 / 126)$ of the $\mathrm{CD}$ patients showed clinical response and $49.1 \%(53 / 126)$ showed clinical remission at the end of 6 weeks. Up to $77 \%(57 / 84)$ and $67.6 \%(50 / 84)$ of the UC patients showed clinical response and remission, respectively. At week 30,67.2\% of week-14 responder CD patients (39/79) maintained clinical response and 53.4\% (31/52) achieved clinical remission. Moreover, $80 \%$ of the week-14 responder UC patients (20/45) maintained clinical response and $68 \%(17 / 45)$ achieved clinical remission.

Farkas et al enrolled $18 \mathrm{CD}$ and $21 \mathrm{UC}$ patients in a prospective study that lasted for 8 weeks. ${ }^{10}$ Response and remission was measured using CDAI for CD and the Mayo scoring system for UC. Mucosal healing was defined as Mayo endoscopy subscore of 0 or 1. In $\mathrm{CD}, 6 / 16$ and $8 / 16$ patients had achieved clinical response and remission at week 8 . For the UC patients, $3 / 15$ and $10 / 15$ patients had achieved clinical response and remission at week 8 .
Kang et al administered CT-P13 to 17 subjects with $\mathrm{CD}(n=8)$ or UC $(n=9)$ in a prospective study. ${ }^{11}$ Seven total patients, including $5 \mathrm{UC}$ and $2 \mathrm{CD}$ patients, achieved clinical response and remission.

Park et al conducted a post-marketing study of CT-P13 for safety and efficacy evaluation using a population of 173, composed of 78 UC patients and $95 \mathrm{CD}$ patients. ${ }^{12}$ Among these, 87.2\% (32/39) of the patients with moderate to severe $\mathrm{CD}$ achieved response at week 14 and $79.5 \%(31 / 39)$ at week 30 . Also, 69.2\% (27/39) and 59\% $(23 / 39)$ achieved remission at the same weeks respectively. In cases of moderate to severe UC, $75.5 \%(40 / 53)$ achieved a response at week 14 and $72.2 \%(39 / 54)$ at week 30, with $49.1 \%$ (26/53) at week 14 and $37 \%(20 / 54)$ at week 30 achieving remission.

Keil et al treated 53 patients, including 30 with $\mathrm{CD}$ and 22 with UC, with CT-P13 for 14 weeks. ${ }^{13}$ All patients in the CD group achieved remission or clinical response in 14 weeks, whereas for the patients with UC, only 9 achieved remission and 12 achieved partial response to therapy.

Jahnsen et al conducted a prospective, single center, observational study with $46 \mathrm{CD}$ and 32 UC patients. ${ }^{14}$ Efficacy in the CD patients was assessed by a Harvey-Bradshaw index score of $<$ equal to 4 at week 14; efficacy in the UC patients was assessed by a partial Mayo score as described above. Of the CD patients, $79 \%$ $(34 / 43)$ achieved remission, compared to $56 \%$ (18/32) of the UC patients. 
Efficacy in infliximab-naive $v s$ infliximab-exposed patients

Gecse et al compared efficacy of CT-P13 in infliximab-naïve patients versus patients who were previously exposed to infliximab. ${ }^{20}$ Patients previously exposed to infliximab showed a slight non-significant reduction in clinical response and remission $(66.6 \%$ and $33.3 \%, p=0.35$ vs $84.2 \%$ and $78.9 \%, p=0.06)$.

In another study, $79.5 \%(31 / 39)$ of patients with $\mathrm{CD}$ and $72.2 \%(39 / 54)$ of patients with UC who were also infliximabnaïve achieved clinical response at week 30 , compared to $87.1 \%$ (27/31) of patients with CD and 100\% (11) of patients with UC who achieved disease control/remission when they were switched from infliximab to CT-P13. ${ }^{12}$

Jung et al, in a retrospective multicenter study, reviewed records of patients who had received at least one dose of CT-P13 over a 3-year period. ${ }^{15}$ A total of 51 patients with $\mathrm{UC}$ and 59 with $\mathrm{CD}$ were studied. For CD in infliximab-naïve patients, 95.5\% (21/22) of the patients achieved clinical response and $77.3 \%(17 / 22)$ of the patients achieved remission. For UC in infliximab-naïve patients, $91.3 \%(21 / 23)$ and $47.8 \%(11 / 23)$ of the patients achieved clinical response and remission respectively.

\section{Biochemical response}

In the study performed by Gecse et al, mean C-reactive protein (CRP) levels were found to have decreased from $20.9 \mathrm{mg} / \mathrm{L}$ at baseline to $10.6 \mathrm{mg} / \mathrm{L}$ at week 14 for the $\mathrm{CD}$ patients and 32.4 $\mathrm{mg} / \mathrm{L}$ at baseline to $7.5 \mathrm{mg} / \mathrm{L}$ at week 14 for the UC patients. ${ }^{20}$

In a study by Keil et al, the median CRP levels were found to have decreased from $28 \mathrm{mg} / \mathrm{L}$ in men and $11 \mathrm{mg} / \mathrm{L}$ in women to 1 $\mathrm{mg} / \mathrm{L}$ in men and $5 \mathrm{mg} / \mathrm{L}$ in women $(p=0.011) .{ }^{13}$

Jung et al demonstrated that CRP levels decreased from 2.22 $\mathrm{mg} / \mathrm{L}$ at baseline to $0.56 \mathrm{mg} / \mathrm{L}$ at 30 weeks for the treatment-naïve CD patients and from $1.89 \mathrm{mg} / \mathrm{L}$ at baseline to $0.51 \mathrm{mg} / \mathrm{L}$ at 30 weeks for the treatment-naïve UC patients. ${ }^{15}$ Also, they reported a decrease in erythrocyte sedimentation rate (ESR) from 44 and 27 to 22 and 17 in the CD and UC patients respectively.

In another study, the mean serum CRP levels were significantly reduced at week 14 compared to baseline for $\mathrm{CD}$ patients (4.9 $\mathrm{mg} / \mathrm{L} v s 22.5 \mathrm{mg} / \mathrm{L})$ and for UC patients $(9.6 \mathrm{mg} / \mathrm{L} v s 36.8$ $\mathrm{mg} / \mathrm{L}) .{ }^{14}$

\section{Mucosal healing}

Three studies reported mucosal healing. In the first study, the mean endoscopic Mayo score was 2.6 for the UC patients, and after induction $6 / 15$ of the patients had a score of 1 and $4 / 15$ had a score of $0 .{ }^{11}$ In the second study, $71.8 \%$ (28/39) of the infliximab-naïve patients with UC showed evidence of mucosal healing. ${ }^{12}$ In the third study, $66.7 \%(4 / 6)$ of the patients with UC showed mucosal healing at 30 weeks. $^{15}$

\section{Safety}

Gecse et al reported adverse events in $17.1 \%$ of all patients in their study (35/210). ${ }^{20}$ Among these were 14 cases of infusion reactions, only 4 of which were represented by infliximab-naïve patients; the infusion reactions occurred in a greater proportion of patients who had previous infliximab exposure $(27 \% \mathrm{vs}$
$2.5 \%, p<0.001)$. Infectious adverse events occurred in $5.7 \%$ of the patients, with 1 patient dying due to an invasive fungal infection.

Farkas et al reported only mild arthralgias in their group of CD patients, and in the UC group 2 hypersensitivity reactions with need for colectomy. ${ }^{10}$ Similarly, Kang et al reported 1 UC patient experiencing arthralgia and requiring discontinuation of CT-P13. ${ }^{11}$ In the study by Keil et al, however, a total of 4 complications were identified during the CT-P13 therapy course, represented by pneumonia in 1 patient, herpes labialis in 1 patient, venous thrombosis in 1 patient and allergic reaction in 1 patient. ${ }^{13}$ Park et al described 1 case of tuberculosis, 9 cases $(5.2 \%)$ of infection and 9 cases $(5.2 \%)$ of infusion-related reaction. ${ }^{12}$ Jahnsen et al reported a variety of adverse events, including infusion reaction, skin rash, campylobacter enterocolitis, herpes zoster, herpes simplex, arthralgia and fatigue, pneumonia, erysipelas, elevated transaminases, palpitations and colectomy; with the exception of infusion reaction, which occurred in 2 patients, all other adverse events occurred in one patient each. ${ }^{14}$

\section{Immunogenicity}

Immunogenicity can have a huge impact on the efficacy of biologic therapies; specifically, it is influenced by patient, disease and drug-related factors. Several studies have reported ADA concentrations using assays defined to measure neutralizing antibodies.

Jahnsen et al reported 2 patients with ADA levels $>80$ AU/L, 5 patients with ADA levels between $10 \mathrm{AU} / \mathrm{L}$ and $80 \mathrm{AU} / \mathrm{L}$, and 1 patient with ADA level $<10 \mathrm{AU} / \mathrm{L}$; three of these patients had previously been treated with TNF antagonists. ${ }^{14}$ In another study, ADA were detected at baseline in 9.1\% (9/99) of patients with $\mathrm{CD}$ and $21.3 \%$ of the patients at 14 weeks. ${ }^{20}$ When compared to infliximab-naïve patients, however, the ADA positivity in the infliximab-exposed patients was $38.5 \%(5 / 13)$ versus $16.7 \%(8 / 48)$. In UC patients, the baseline ADA positivity rate was $3.6 \%(2 / 55)$ in the infliximab-naïve patients and $30.8 \%(4 / 13)$ in the infliximabexposed patients; at 14 weeks, the ADA positivity rate was $21.9 \%$ $(7 / 32)$ and $30 \%(3 / 10)$ respectively, and no significant difference was detected in ADA positivity at week 14 between patient groups based on previous infliximab exposure.

\section{Discussion}

The PLANETAS and PLANETRA studies demonstrated equivalent PKs for both infliximab and CT-P13 in RA and AS patients. There was, however, an increased clearance of infliximab in patients with IBD, which was attributed to several factors, including fecal loss of drug, which also causes reduced albumin. Low albumin levels are associated with increased clearance of infliximab in patients with $\mathrm{UC}$ and $\mathrm{CD}$. Indeed, loss of infliximab through feces has been reported in patients with severe UC. ${ }^{26-29}$

\section{Interchangeability}

Interchangeability and automatic substitution indicates that a biosimilar may be substituted for the innovator product without intervention of the healthcare provider. It is different from 'switching', which is the transition from the innovator product to the biosimilar or vice versa and is based on the physician's decision. ${ }^{7}$ While no 
biosimilar drug has been designated as 'interchangeable' yet, there have been studies demonstrating effective single transitions from innovator product to biosimilar with no new safety or immunogenicity changes noted. ${ }^{24,30,31}$

Data from the PLANETRA study showed that ADA to infliximab cross-react with CT-P13 and vice versa, indicating that development of antibodies to either the originator or biosimilar will cross-react with the other drug, so that the patient will not benefit from switching. However, cross-reactivity has not been reported with adalimumab, leaving open the possibility of switching to either originator infliximab or the biosimilar in case of ADA development to adalimumab.

\section{Indication extrapolation}

Extensive in vitro studies are required by the FDA, EMA and Health Canada to prove similarity in quality for the innovator drug and biosimilar. Also, clinical and non-clinical studies are required to demonstrate similarity in PKs, efficacy and adverse events. When such studies are performed in a subset of patients with a particular condition, the results may then be extrapolated across different clinical conditions at the request of the sponsor. Thus far, the EMA, Health Canada and FDA, along with several other regulatory health agencies, have approved the use of CT-P13 across all conditions for infliximab based on extrapolation. Health Canada, however, has not approved CT-P13 for UC and CD in accordance with concerns raised by several gastroenterological groups about a difference in mechanism of action of infliximab in patients with IBD. ${ }^{19}$

Based on available data from current preclinical and clinical studies, there is little to dissuade the use of CT-P13 across indications for the originator, especially in infliximab-naïve patients. There is preliminary evidence about switching from the originator to CT-P13 with apparently no adverse effects. ${ }^{32}$ Approval by leading regulatory bodies is encouraging, may hugely impact the future of IBD management and will also lead to further information about the long-term safety and efficacy of this drug.

\section{Future directions}

The main motivator for the use of biosimilars is the immense financial benefit they provide, with a recent analysis estimating a cost reduction between 10 million to 335 million Euros over the next 5 years. ${ }^{33}$

More long-term data, however, is needed, especially for patients in remission who are on the originator drug and are then switched to the biosimilar; these studies need to assess the maintenance of efficacy and carry out long-term monitoring of side effects. Headto-head comparisons of infliximab and CT-P13 in patients with IBDs would ideally be the next step. Furthermore, there is need for further validation of serum CT-P13 assays and antibody detection. CT-P13 is the first of many biosimilars to existing monoclonal antibodies that are either in early clinical trials or being developed. More studies on the real impact on healthcare resource utilization are required in the coming years, in addition to robust pharmacovigilance and post marketing research.

\section{Conflict of interest}

The authors have no conflict of interests related to this publication.
Author contributions

Composing the manuscript (DK, RC), approving the final manuscript (RC).

\section{References}

[1] Rizzo G, Pugliese D, Armuzzi A, Coco C. Anti-TNF alpha in the treatment of ulcerative colitis: A valid approach for organ-sparing or an expensive option to delay surgery?. World J Gastroenterol 2014;20(17):4839-4845. doi:10.3748/wjg.v20.i17.4839.

[2] Stidham RW, Lee TC, Higgins PD, Deshpande AR, Sussman DA, Singal $A G$, et al. Systematic review with network meta-analysis: the efficacy of anti-tumour necrosis factor-alpha agents for the treatment of ulcerative colitis. Aliment Pharmacol Ther 2014;39(7):660-671. doi:10.1111/apt.12644.

[3] Schnitzler F, Fidder H, Ferrante M, Noman M, Arijs I, Van Assche $\mathrm{G}$, et al. Long-term outcome of treatment with infliximab in 614 Crohn's disease patients: results from a single centre cohort. Gut 2009;58(4):492-500. doi:10.1136/gut.2008.155812.

[4] Ollendorf DA, Lidsky L. Infliximab drug and infusion costs among patients with Crohn's disease in a commercially-insured setting. Am J Ther 2006;13(6):502-506. doi:10.1097/01.mjt.0000245223.43783.45.

[5] Jha A, Dunlop A, Upton W. Budget impact analysis of introducing biosimilar infliximab for the treatment of auto immune disorders in five European countries. Value Health 2014;17(7):A525. doi:10.1016/j. jval.2014.08.1655.

[6] McKeage K. A review of CT-P13: An infliximab biosimilar. BioDrugs 2014;28:313-321. doi:10.1007/s40259-014-0094-1.

[7] CDER/CBER FDA. Scientific Considerations in Demonstrating Biosimilarity to a Reference Product Guidance for Industry Scientific Considerations in Demonstrating Biosimilarity to a Reference Product. Guid Ind. 2015;(February).

[8] Gecse KB, Khanna R, van den Brink GR, Ponsioen CY, Löwenberg $\mathrm{M}$, Jairath $\mathrm{V}$, et al. Biosimilars in IBD: hope or expectation?. Gut 2013;62(6):803-807. doi:10.1136/gutjnl-2012-303824.

[9] Beck A, Reichert JM. Approval of the first biosimilar antibodies in Europe: A major landmark for the biopharmaceutical industry. MAbs 2013;5(5):621-623. doi:10.4161/mabs.25864.

[10] Farkas K, Rutka M, Bálint A, Nagy F, Bor R, Milassin Á, et al. Efficacy of the new infliximab biosimilar CT-P13 induction therapy in Crohn's disease and ulcerative colitis - experiences from a single center. Expert Opin Biol Ther 2015;15(9):1257-1262. doi:10.1517/14712598.2 015.1064893.

[11] Kang YS, Moon HH, Lee SE, Lim YJ, Kang HW. Clinical Experience of the Use of CT-P13, a Biosimilar to Infliximab in Patients with Inflammatory Bowel Disease: A Case Series. Dig Dis Sci 2015;60(4):951956. doi:10.1007/s10620-014-3392-z.

[12] Park SH, Kim Y-H, Lee JH, Kwon HJ, Lee S-H, Park D Il, et al. Postmarketing study of biosimilar infliximab (CT-P13) to evaluate its safety and efficacy in Korea. Expert Rev Gastroenterol Hepatol 2015;9(sup1):35-44. doi:10.1586/17474124.2015.1091309.

[13] Keil R, Wasserbauer M, Zádorová Z, Hajer J, Drastich P, Wohl P, et al. Clinical monitoring: infliximab biosimilar CT-P13 in the treatment of Crohn's disease and ulcerative colitis. Scand J Gastroenterol 2016;51(9):1062-1068. doi:10.3109/00365521.2016.1149883.

[14] Jahnsen J, Detlie TE, Vatn S, Ricanek P. Biosimilar infliximab (CT-P13) in the treatment of inflammatory bowel disease: A Norwegian observational study. Expert Rev Gastroenterol Hepatol 2015;9(Suppl 1):45-52. doi:10.1586/17474124.2015.1091308.

[15] Jung YS, Park D II, Kim YH, Lee JH, Seo PJ, Cheon JH, et al. Efficacy and safety of CT-P13, a biosimilar of infliximab, in patients with inflammatory bowel disease: A retrospective multicenter study. J Gastroenterol Hepatol 2015;30(12):1705-1712. doi:10.1111/jgh.12997.

[16] Blandizzi C, Gionchetti P, Armuzzi A, Caporali R, Chimenti S, Cimaz R, et al. The Role of Tumour Necrosis Factor in the Pathogenesis of Immune-Mediated Diseases. Int J Immunopathol Pharmacol 2014;27(1 Suppl):1-10. doi:10.1177/03946320140270S101. 
[17] European Medicines Agency. Assessment report: REMSIMA. Epar [Internet]. 2013;EMA/CHMP/5(June). Available from: 03-03-2014.

[18] Long EO, Sik Kim H, Liu D, Peterson ME, Rajagopalan S. Controlling Natural Killer Cell Responses: Integration of Signals for Activation and Inhibition. Annu Rev Immunol 2013;31(1):227-258. doi:10.1146/annurev-immunol-020711-075005.

[19] Van den Brande JMH, Braat $\mathrm{H}$, Van den Brink GR, Versteeg $\mathrm{HH}$, Bauer CA, Hoedemaeker I, et al. Infliximab but not etanercept induces apoptosis in lamina propria T-lymphocytes from patients with Crohn's disease. Gastroenterology 2003;124(7):1774-1785. doi:10.1016/ S0016-5085(03)00382-2.

[20] Gecse KB, Lovász BD, Farkas K, Banai J, Bene L, Gasztonyi B, et al. Efficacy and safety of the biosimilar infliximab CT-P13 treatment in inflammatory bowel diseases: a prospective, multicentre, nationwide cohort. J Crohn's Colitis 2016;10(2):133-140. doi:10.1093/ecco-jcc/ jjv220.

[21] Park W, Hrycaj P, Jeka S, Kovalenko V, Lysenko G, Miranda P, et al. A randomised, double-blind, multicentre, parallel-group, prospective study comparing the pharmacokinetics, safety, and efficacy of CT-P13 and innovator infliximab in patients with ankylosing spondylitis: the PLANETAS study. Ann Rheum Dis 2013;72(10):1605-1612. doi:10.1136/annrheumdis-2012-203091.

[22] Louis E, El Ghoul Z, Vermeire S, Dall'Ozzo S, Rutgeerts P, Paintaud $\mathrm{G}$, et al. Association between polymorphism in IgG Fc receptor IIla coding gene and biological response to infliximab in Crohn's disease. Aliment Pharmacol Ther 2004;19(5):511-519. doi:10.1111/j.13652036.2004.01871.x.

[23] Vos ACW, Wildenberg ME, Duijvestein M, Verhaar AP, Van Den Brink GR, Hommes DW. Anti-tumor necrosis factor- $\alpha$ antibodies induce regulatory macrophages in an Fc region-dependent manner. Gastroenterology 2011;140(1):221-230. doi:10.1053/j.gastro.2010.10.008.

[24] Yoo DH, Prodanovic N, Jaworski J, Miranda P, Ramiterre E, Lanzon A, et al. Efficacy and safety of CT-P13 (biosimilar infliximab) in patients with rheumatoid arthritis: comparison between switching from reference infliximab to CT-P13 and continuing CT-P13 in the PLANETRA extension study. Ann Rheum Dis 2017;76(2):355-363. doi:10.1136/ annrheumdis-2015-208786.

[25] Malíčková K, Ďuricová D, Bortlík M, Hind'oš M, Machková N, Hrubá $\mathrm{V}$, et al. Serum trough infliximab levels: A comparison of three dif- ferent immunoassays for the monitoring of CT-P13 (infliximab) treatment in patients with inflammatory bowel disease. Biologicals 2016;44(1):33-36. doi:10.1016/j.biologicals.2015.09.005.

[26] Fasanmade AA, Adedokun OJ, Blank M, Zhou H, Davis HM. Pharmacokinetic Properties of Infliximab in Children and Adults with Crohn's Disease: A Retrospective Analysis of Data from 2 Phase III Clinical Trials. Clin Ther 2011;33(7):946-964. doi:10.1016/j. clinthera.2011.06.002.

[27] Fasanmade AA, Adedokun OJ, Ford J, Hernandez D, Johanns J, Hu C, et al. Population pharmacokinetic analysis of infliximab in patients with ulcerative colitis. Eur J Clin Pharmacol 2009;65(12):1211-1228. doi:10.1007/s00228-009-0718-4.

[28] Xu Z, Seitz K, Fasanmade A, Ford J, Williamson P, Xu W, et al. Population pharmacokinetics of infliximab in patients with ankylosing spondylitis. J Clin Pharmacol 2008;48(6):681-695. doi:10.1177/0091270008316886.

[29] Brandse JF, van den Brink GR, Wildenberg ME, van der Kleij D, Rispens T, Jansen JM, et al. Loss of Infliximab Into Feces Is Associated With Lack of Response to Therapy in Patients With Severe Ulcerative Colitis. Gastroenterology 2015;149(2):350-355. doi:10.1053/j. gastro.2015.04.016.

[30] Sieczkowska J, Jarzębicka D, Banaszkiewicz A, Plocek A, Gawronska A, Toporowska-Kowalska E, et al. Switching Between Infliximab Originator and Biosimilar in Paediatric Patients with Inflammatory Bowel Disease. Preliminary Observations. J Crohns Colitis 2016;10(2):127132. doi:10.1093/ecco-jcc/jjv233.

[31] Park W, Yoo DH, Miranda P, Brzosko M, Wiland P, Gutierrez-Ureña S, et al. Efficacy and safety of switching from reference infliximab to CTP13 compared with maintenance of CT-P13 in ankylosing spondylitis: 102-week data from the PLANETAS extension study. Ann Rheum Dis 2017;76(2):346-354. doi:10.1136/annrheumdis-2015-208783.

[32] Smits LJ, Derikx LA, de Jong DJ, Boshuizen RS, van Esch AA, Drenth JP, et al. Clinical outcomes following a switch from Remicade(R) to the biosimilar CT-P13 in inflammatory bowel disease patients: a prospective observational cohort study. J Crohns Colitis 2016;10(11):12871293. doi:10.1093/ecco-jcc/jjw087.

[33] Brodszky V, Baji P, Balogh O, Pontek M. Budget impact analysis of biosimilar infliximab (CT-P13) for the treatment of rheumatoid arthritis in six Central and Eastern European countries. Eur J Health Econ 2014(Suppl 1):S65-S71. doi:10.1007/s10198-014-0595-3. 